[Vicino Oriente XXII (2018), pp. 15-28]

\title{
3D SCANNING, MODELLING AND PRINTING \\ OF ULTRA-THIN NACREOUS SHELLS FROM JERICHO: A CASE STUDY OF SMALL FINDS DOCUMENTATION IN ARCHAEOLOGY
}

\author{
Lorenzo Nigro* - Luciano Fattore ${ }^{\circ}$ - Daria Montanari ${ }^{+}$ \\ Sapienza University of Rome
}

This paper springs out from a collaborative project jointly carried out by the FabLab Saperi\&Co and the Museum of Near East, Egypt and Mediterranean of Sapienza University of Rome focused at producing replicas of ultra-thin archeological finds with a sub-millimetric precision. The main technological challenge of this project was to produce models through $3 D$ optical scanning (photogrammetry) and to print faithful replicas with additive manufacturing.

The objects chosen for the trial were five extremely fragile and ultra-thin nacreous shells retrieved in Tell es-Sultan/ancient Jericho by the Italian-Palestinian Expedition in spring 2017, temporarily on exhibit in the Museum. The experiment proved to be successful, and the scanning, modeling and printing of the shells also allowed some observations on their possible uses in research and museum activities.

Keywords: 3D model; 3D print; photo-modeling; FabLab; additive manufacturing

\section{INTRODUCTION}

The retrieval in Tell es-Sultan, ancient Jericho, ${ }^{1}$ of a set of five nacreous shells imported from the Nile to the renowned city of Palestine in the $3^{\text {rd }}$ millennium BC, at the time of the I-II Dynasties of Egypt, was an unexpected archaeological discovery, which added a new tessera to the mosaic of the Egyptian-Levantine relationships during the formative stage of the Early Bronze Age. ${ }^{2}$ These amazing finds, which were traded as luxury goods and served as containers of dioxide of manganese, that is the ancient eye liner for make-up of male and female members of the local élite, were brought to the Museum VOEM in Sapienza University, Rome, and underwent a series of chemical-physical analyses together with a careful restoration made by Salvatore Tricoli. The shells proved to be extremely fragile with their peel splitting apart.

While waiting to ship them back to Palestine, the shells have been set on exhibit in the Museum and the decision was taken to produce high-quality replicas in the FabLab Saperi\&Co of Sapienza University of Rome.

\footnotetext{
Department of Oriental Studies, Sapienza University of Rome.

FabLab Saperi\&Co, Sapienza University of Rome.

Curator of Museum of Near East, Egypt and Mediterranean, Sapienza University of Rome.

The joint Italian-Palestinian Expedition to Tell es-Sultan/ancient Jericho is active since 1997 and it is fruitfully carried on by Sapienza University of Rome and the Department of Archaeology and Cultural Heritage - Ministry of Tourism \& Antiquities of Palestine with the financial support of the Italian Ministry of Foreign Affairs.

$2 \quad$ Nigro et al. 2018.
}

ISSN 0393-0300

e-ISSN 2532-5159 


\section{TRIDIMENSIONAL REPLICAS OF SHELLS [L.F.]}

The main goal of this work was to obtain physical replicas of 4 Nilotic shells found at Tell es-Sultan/ancient Jericho, dating back to 5000 years ago. ${ }^{3}$ All the steps of the process were contactless with regards of the findings except for their positioning operations.

\subsection{Premise}

More than twenty years of applying 3D survey to objects, artworks and buildings, based on different techniques have led to a plethora of projects involving museums, universities, foundations and cultural heritage at large. The first broad impact project, the "Digital Michelangelo Project”, dates back to last years of twentieth century. ${ }^{4}$

Several goals have been sorted out for digital 3D in cultural heritage: digital archives of 3D models, high fidelity physical replica of artworks, remote fruition of cultural heritage, digital restoration, monitoring of cultural heritage ${ }^{5}$ as well as sensory experiences involving touch, smell and sound. ${ }^{6}$ Among these, replicas of artworks covers at least ten years. Replicas have been used for preservation, restoration, analysis, education, accessibility, research, musealization and merchandise. Very few best practices exist to date for this kind of reproductions ${ }^{7}$ that doesn't follow the paradigms and needs of industrial and design additive manufacturing. Based upon this lack of standards, a lot of different workflows have been proposed both for the digital acquiring of the shape and for the physical reproduction of the objects.

Before using 3D scanners the techniques (silicone rubber or gypsum molds) used to make copies of objects, despite the high details and precision achieved and the nice looking of the replica, were fairly invasive and sometimes destructive. Otherwise early digital acquiring of shapes and their physical reproduction consisted in expensive and complicate tasks, relegating the attempts to few research projects.

Methods concerning the acquisition, nowadays, range over mechanical picking points, laser scanning, CT scans, structured light scanning, classical photogrammetry and structure from Motion (digital photogrammetry). Replicas mainly rely on stereolithography (SLA), Digital Light Processing (DLP), Selective Laser Sintering (SLS) and Fused Deposition Modeling (FDM). Also the quality required for the digital and the physical models are very heterogeneous, depending on the methodology, the computational gap, the ability of the performers and of course on the updating of the involved technologies.

3D application in archaeology and in cultural heritage have spread worldwide, ranging from entire ancient cities to small cylinder seals and coins passing through human bones and musical instruments. Little and tricky objects like our mother of pearl shells can represent a valid test for improving techniques and instruments.

We disclose that the choice of survey methodology has fallen upon photogrammetry ( $\S$ 2.2.) while the reproduction has been performed by SLA (§ 2.3.).

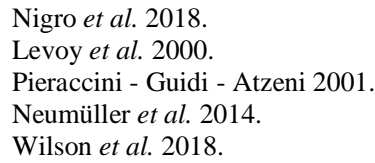




\subsection{Photogrammetric workflow and equipment}

Normal photogrammetric workflow prescribes to take a certain number of partially overlapping photos obtained gradually moving inside a room or around an object from different viewpoints (higher the complexity of the objects, largest the number of required viewpoints).

Close range photogrammetry relies on quite common equipment regarding camera, lenses and lighting. Basic rig consists in a quite cheap 10 megapixel camera and a good light source. Doubtless high-quality equipment significantly increases the resulting model quality and allows conveniently facing up some peculiar situations. Our shells represent good examples of these situations. They are small, high curvature, extremely thin, shiny objects. These issues require some extra hardware and software associated with nonconventional photographic techniques, such as polarizing filters and focus stacking.

\subsubsection{Photographic equipment}

A Nikon D7200, aps-c 24,2 megapixel camera, equipped with a Sigma 17-70 f/2.8-4 DC MACRO OS HSM lens have been used. A circular polarizing filter has been applied to the lens. The camera stands on a Gitzo fiber carbon tripod with a Manfrotto 410 head. We remote control the camera via usb tethering cable and digiCamControl, free software that completely remote controls the camera. All the raw shoots have been saved on two separate hard disks to minimize the risks of data loss. The size of each file is about 21 megabytes.

\subsubsection{Lighting and light measurement}

Two 100 watt fluorescent lamps have been disposed at $45^{\circ}$ respect to the camera, each one equipped with a linear polarizing sheet. These are the only light sources used for the photographic set. The intensity of the light has been measured with a Minolta Autometer III light meter in order to choose the correct required exposure time for the small selected aperture $(f / 20)$. Narrow aperture is necessary to increase depth of field but implies long exposure time, making mandatory the use of a tripod. This couple of values (time/aperture) never changed during the shooting of a single shell.

\subsubsection{Posing the shells and shooting}

Each shell has been photographed starting from two poses. First of all, the valve was posed standing on an extremity (fig.1), on a turntable, at approximately $50 \mathrm{~cm}$ from the camera. A reference scale bar was included in the set. Secondly, a strip of photos, with different focus, has been shooted. Depending on the position of the valve, a minimum of 5 (valve parallel to the sensor) to a maximum of 30 (valve perpendicular to the sensor) photos are necessary to resolve the small depth of field issue. Afterward a $15^{\circ}$ rotation of the turntable let us to change the point of view of the valve in respect of the camera.

Another strip of photos with different focus (from near to far) has been taken. Ideally 24 rotations, of $15^{\circ}$ each, would be enough to include sufficient common features in two consecutive photos and properly align all the photos. However, dealing with small thickness objects, would be better to decrease the angle of rotation as soon as the shell approximates to the perpendicularity with the sensor. After a complete rotation, the shell 
has been posed upside down (fig. 2) and a complete set of photos, like the one described before, was taken.

\subsubsection{Images post-production}

The use of lossless raw instead of jpeg files, despite adding a time consuming step to the workflow, allows to significantly improving the quality of images. Raw files advantages essentially stand in wider bit depth and dynamic range, they, store 12 or 14 bits of information reproducing to 68 billion or 4,3 trillion colors. This not also concern quality color but is a great improvement in recovering dark underexposed areas of high contrast images. When trying to photograph tricky objects like shells one can decide to underexpose to minimize the reflection and to later recover details in the resulting dark shadows. Dynamic range is the ability to record the gradual transition between the high lights and the shadows. The initial raw postproduction has been performed with a common raw editor (darktable, ufraw, RawTherapee to name a few); all the pictures have been corrected for highlights reduction, shadows and noise. The correction applied to a concave side photo (that is affected by a lot of specular reflexes) has been extended to all the photos of a set.

Second step of postproduction consists in focus stacking. More than 500 images for each set have been grouped according to their rotation on the turntable. At least 24 groups of photos (corresponding to $15^{\circ}$ rotation) have been elaborated with Zerene Stacker, a focus stacking software. The result consists in a single photo for each group, with extended depth of field (fig. 3).

Last step of post-production has been performed in an image editor (the Gimp, Adobe Photoshop) to completely remove all the non-shell features (fig. 4; fig. 1).

\subsubsection{Pictures aligning, point cloud generation and meshing}

The resulting images have been processed with Agisoft Photoscan 1.4.0 standard edition to align them and produce a high resolution point cloud (tab. 1). A point cloud basically is an array of at least three numbers for each detected point of an object. These three values represent the XYZ coordinates in a spatial reference system. Photoscan does not provide a reliable noise reduction function and then we only export a point cloud .ply file.

Scaling, noise removal and meshing of the point cloud have been performed with CloudCompare 2.9.1. CloudCompare uses Poisson Surface Reconstruction method (with an octree depth value of 10 has) for reconstruct a mesh from a point cloud. A mesh is the set of vertices (the points on the point cloud), edges (the lines connecting one point to another point) and faces (the triangular area enclosed in three edges) that describe a 3D shape. Small defects in the mesh have been removed and holes have been closed with Meshlab 2016 and Blender v 2.79 .

\begin{tabular}{|l|c|c|c|c|c|}
\hline SHELL & $\begin{array}{l}\text { VOLUME } \\
\text { MM3 }\end{array}$ & $\begin{array}{l}\text { SURFACE } \\
\text { MM2 }\end{array}$ & $\begin{array}{l}\text { NUMBER } \\
\text { OF POINTS }\end{array}$ & $\begin{array}{l}\text { NUMBER } \\
\text { OF FILTERED POINTS }\end{array}$ & $\begin{array}{l}\text { NUMBER } \\
\text { OF FACES }\end{array}$ \\
\hline TS.17.F.L135.1 & 8.925 & 11.000 & 14.658 .627 & 7.181 .885 & 2.384 .346 \\
\hline TS.17.F.L135.2 & 16.368 & 16.651 & 18.457 .869 & 10.866 .122 & 3.863 .518 \\
\hline TS.17.F.L135.3 & 19.959 & 18.462 & 15.844 .612 & 8.821 .241 & 3.980 .756 \\
\hline TS.17.F.L135.4 & 14.007 & 13.481 & 18.531 .077 & 11.221 .643 & 5.182 .602 \\
\hline
\end{tabular}

Tab.1 - Summary of the geometric information. 


\subsection{Additive manufacturing (3D printing)}

In SLA (stereo-lithography apparatus) manufacturing, photosensitive thermoset polymers are selectively cured by an ultraviolet laser beam to create an object layer by layer. The final watertight models have been 3D printed with a SLA printer Formlabs Form2, with a $405 \mathrm{~nm}$ violet laser, using a resin Clear V2 (FLGPCL02) at a resolution of $0.05 \mathrm{~mm}$ (fig. 5). Printing time amounts to 6 hours. Final step is represented by post curing in a chamber (fig. 6), with an UV between 315 and $400 \mathrm{~nm}$ wavelength, to stabilize the mechanical properties of the reproduction. The replicas are transparent due to the use of clear resin.

\subsection{Critical issues in geometry acquisition}

\subsubsection{Photogrammetry overcomes laser/structured light scanning}

The tridimensional documentation of shell valves presents two main critical issues: small thickness and extremely reflective curved surface. Depending on the typology of the hardware, could be difficult align, in one model, the two faces of the thin valve. Continuously rotating objects under a laser beam or under a pattern of structured light are correctly surveyed regardless of their thickness. On the other hand shiny, high curvature objects produce too much and scattered reflection of the laser or of the visible radiation. More control on the light sources is needed. Albeit amplifies the problem of aligning two faces of a thin volume, cross polarization photogrammetry allows to override or minimize the last issue. Far from being only an esthetic matter, the reflections produce several defects and holes in the generated model, often making it unusable. Anyway, for small and medium size objects and distances, close range photogrammetry seems to have an advantage in terms of methodology and accuracy. ${ }^{8}$

\subsubsection{Basic principles of photogrammetry}

Digital photogrammetry is an evolution of analog one, mainly used, for metrical and mapping purposes, on aerial photos. Analog photogrammetry requires calibrated cameras, and a certain number of ground control points to correlate features 2D coordinates in the images with corresponding 3D coordinates in the landscape or on objects. Increased computational capabilities of computers and cameras and new algorithms allow redundant points in the pictures to be used to recover information about the lost dimension without using calibrated cameras and, in some cases, without ground control points of known coordinates. These algorithms, inspecting photos, automatically resolve the relationship between camera positions and the location of features on the images. ${ }^{9}$

We can further distinguish aerial from close range photogrammetry depending on the position of the camera in relation to the surveyed surface. The last one contemplates the use of the camera on a tripod and has an action range of few to some tens of meters. Whatever it is the category, photogrammetry gathers mainly geometric (the shape of the objects and

Skarlatos - Kiparissi 2012.

$9 \quad$ Westoby et al. 2012. 
features and their relative position) and physical (principally the electromagnetic emission of an object or part of this, i.e. the colors) information.

Essentially single image doesn't provide any information about size and position of an object, since a point on the film (or on the sensor of the camera) corresponds to infinite points on the imaginary line traced from the real object to the optical center of the camera. To univocally determine the real position in the space we need to know the precise position of the point in two images and the positions and the orientations of the camera during the shoots. Modern software is capable to resolve these uncertainties by "only" inspect the images and the position of redundant features on them.

\subsubsection{Cross polarization photogrammetry to avoid glares}

Arduous problem to resolve dealing with such an object is represented by its particular shape and finishing. Both high curvature and extremely shining surface contribute to scatter away the incident light. As consequence some pixels of the sensor receive too much light and cannot register details other than pure white. Of course these pixels cannot provide features to be used to align the cameras and, even worse, to locate the correspondent points in the space. The resulting point cloud would be very noisy and unreliable, concerning those areas.

Regular light propagates sinusoidally along infinite planes in space. Placing a polarizing filter on the lens of the camera used for photogrammetric reconstruction, drops down most of the light reflected by water or other shiny surfaces, letting the light propagates only in one plane. If we use other polarizing filters on the light sources and rotate them conveniently, we can eliminate almost every reflection (fig. 7).

\subsubsection{Dealing with shells' extreme thickness}

Once successfully resolved the glare problems we have to face the aligning issue due to the thickness of the valve.

When the subject is a little object, one can choose to put it on a turning table and the camera fixed on a tripod. The smaller the angle of rotation between two consecutive shoots, the better will be the overlap between images and the higher will be the chance to correctly align two opponent faces of a thin object.

A further issue arises facing with close up images: that means, even with small aperture, a reduced depth of field, the in-focus part of a photographic image. To deal with this we have used a technique called focus stacking. For each rotation of the turn table, at least 5 images (but often more than 30) have been captured each one differing from the others for the focus. The fusion of the images of a single set produces a single image with an extended depth of field that significantly increases the quality and precision of the resulting $3 \mathrm{~d}$ model. More than 1000 shoots for each shell produce on average 79 high depth of field images for each shell.

\subsection{Future improvements of the workflow}

Though the results are satisfactory, further improvement are connected with the possibility of printing a fine and accurate 3D replica with multicolor CMYK printers. Our transparent sea shells are far from the complex chromatic look of the originals. 
Furthermore, new methods to get a better texture reconstruction are necessary, as well as a different replica techniques or colorization method. Direct 3D color printing, through other technologies (Mcor Iris HD color paper 3D printing and ColorJet 3D) would benefit from improvement of the lighting methods and in the texturing 3D model.

\section{3D REPLICAS IN MUSEUM EXHIBITS [D.M.]}

3D scanning, modeling and printing may find interesting application in museology and preservation, as well as in archeological investigations on small finds. ${ }^{10}$ These techniques are more accurate than human eyes and can capture a high level of details, since almost invisible particulars can be revealed as never before. Hence, objects can be studied with much more details than with traditional pictures. Moreover, 3D scanning and printing, without stress for original items, can be used jointly for restoration (restorative 3D scanning) because they are safe and contactless. This allows to exceed the limit of untouchability, fragility, and lifetime of monuments, objects and finds, through 3D reconstruction.

In addition, 3D is easily shared by scholars, improving studies and scientific debate.

Museums can take an advantage of augmented reality and 3D printing, generating more immersive and attractive experiences. 3D technologies open new doors also for visitors who can manipulate 3D printed versions, without damaging the originals, and make virtual visit to museums. Moreover, this new type of museum reality offers a touchable knowledge that can somehow bridge that part of information previously precluded to visually impaired visitors and students with difficulties in learning.

Thanks to these technological achievements, museum can propose itself at first as a research place, then, as a place for education, and dissemination. ${ }^{11}$

Modeling and additive manufacturing make available fragile and rare objects, previously unavailable, to touch and to move, as it is in the case of nacreous shells from Tell es-Sultan/Jericho (§ 3.1.).

\subsection{Digital engagement of the Museum of Near East, Egypt and Mediterranean}

The discovery of the cache of Nilotic shells made during the excavation of spring 2017 at Tell es-Sultan/Jericho, due to the flimsiness and the state of conservation of finds, constituted the customized test situation to try to apply additive manufacturing to archaeological items for the sake of study of their physical construction.

Reproduction of Chambardia rubens specimens (figs. 8-10) moves in the 'maker' direction. ${ }^{12}$ The four replicas (fig. 8), in fact, represent objects that can be touched without risk by archaeologists, exposed without problems of conservation, and that can easily be

10 As regards museums and new digital challenges see: Visser 2013; Roussou et al. 2015; Sunderland Bowe 2016.

11 In the next future, maybe museums could use data generated by visitors, to improve immersive experiences, to disseminate and to exchange culture, creating a more updated and dynamic synergy between past and future (cf. Museums in the Digital Age) perhaps becoming a maker museum one day (Pignatelli 2013, 156. www.themuseumofthefuture.com/2017/03/07/mixing-museums-and-makers/.).

12 Sharples et al. 2013, 33-35. 
transported to other museums, as well as constituting a further possibility of dissemination like the other kind of replicas.

3D scanning and modeling of Chambardia rubens mussels allow to study in minute detail that rare class of finds, and to make a restorative printing for damaged items, allowing a better understanding of original use and characteristics of these finds.

\section{REFERENCES}

HARgRAVE, J. - MistRy, R.

$2014 \quad$ Museums in the Digital Age, London 2014.

Levoy, M. - Pulli, K. - Curless, B. - Rusinkiewicz, S. - Koller, D. - Pereira, L. - Ginzton, M. ANDERSON, S. - DAVIS, J. - GiNSBERG, J. - SHADE, J. - FULK, D.

2000 The digital Michelangelo project: 3D scanning of large statues: Proceedings of the 27th annual conference on Computer graphics and interactive techniques (Siggraph 2000), New York 2000, pp. 131-144.

NEUMÜLleR, M. - REICHINGER, A. - RIST, F. - KERN, C.

2014 3D Printing for Cultural Heritage: Preservation, Accessibility, Research and Education: M. IOANNIDES - E. QUAK (eds.), 3D Research Challenges in Cultural Heritage. Lecture Notes in Computer Science, vol 8355, Berlin - Heidelberg 2014, pp. 119-134.

Nigro, L. - Montanari, D. - Yasine, J. - MuRa, F. - Rinaldi, T.

2018 A hoard of Nilotic nacreous shells from Egypt to Jericho (Early Bronze II, 3000-2800 BC): Their finding, content and historical archaeological implications: Palestine Exploration Quarterly 150/2 (2018), pp. 110-125.

PieracCini, M. - Guidi, G. - ATZENI, C.

2001 3D digitizing of cultural heritage: Journal of Cultural Heritage 20 (2001), pp. 63-70. Pignatelli, F.

2013 L'evoluzione della stampa 3D e le sue applicazioni in campo museale: Scientific Research and Information Technology 3/2 (2013), pp. 143-158.

Roussou, M. - Pujol, L. - KATIFORI, A. - Perry, S. - VAyAnou, M.

2015 The museum as digital storyteller: Collaborative participatory creation of interactive digital experiences: MW2015: Museums and the Web 2015. Published January 31, 2015, www.mw2015.museumsandtheweb.com/paper/the-museum-as-digital-storytellercollaborative-participatory-creation-of-interactive-digital-experiences/.

Sharples, M. - McAndrew, P. - Weller, M. - Ferguson, R. - FitzGerald, E. - Hirst, T. -

GAVED, M.

2013 Exploring new forms of teaching, learning and assessment, to guide educators and policy makers, Milton Keynes 2013.

SKARLATOS, D. - KIPARISSI, S.

2012 Comparison of laser scanning, photogrammetry and SFM-MVS pipeline applied in structures and artificial surfaces: ISPRS annals of the photogrammetry, remote sensing and spatial information sciences 3 (2012), pp. 299-304.

SUNDERLAND BOWE, J-A.

2016 The Creative Museum - Analysis of selected best practices from Europe, 2016.

VISSER, J.

2013 Perspectives on Digital Engagement with Culture and Heritage: History News 68/3 (2013), pp. 7-13. 
Westoby, M.J. - Brasington, J. - Glasser, N.F. - HAMBrey, M.J. - ReynOlds, J.M.

2012 'Structure-from-Motion' photogrammetry: A low-cost, effective tool for geoscience applications: Geomorphology 179 (2012), pp. 300-314.

Wilson, P.F. - Stott, J. - Warnett, J.M. - AtTRidge, A. - Paul Smith, M. - Williams, M.A

2018 Museum visitor preference for the physical properties of 3D printed replicas: Journal of Cultural Heritage, doi.org/10.1016/j.culher.2018.02.002. 


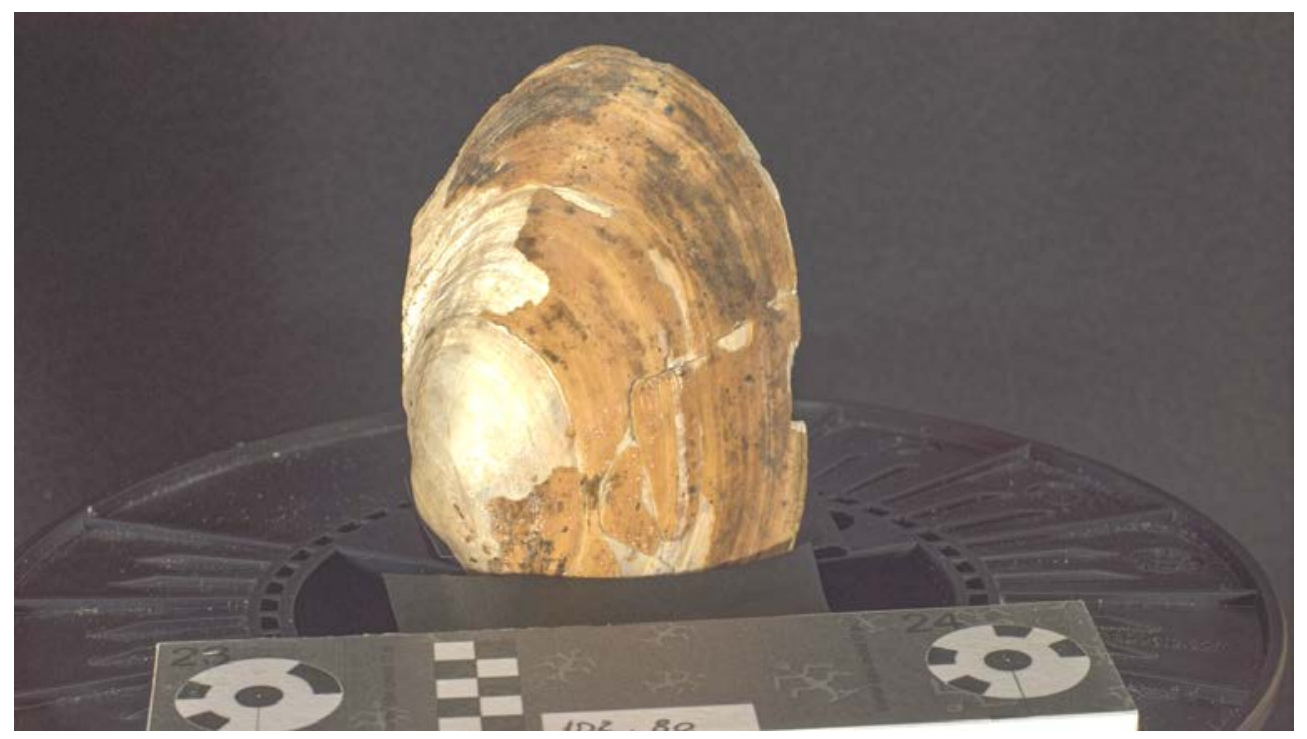

Fig. 1 - The shell stands on one extremity during the first set of photos.

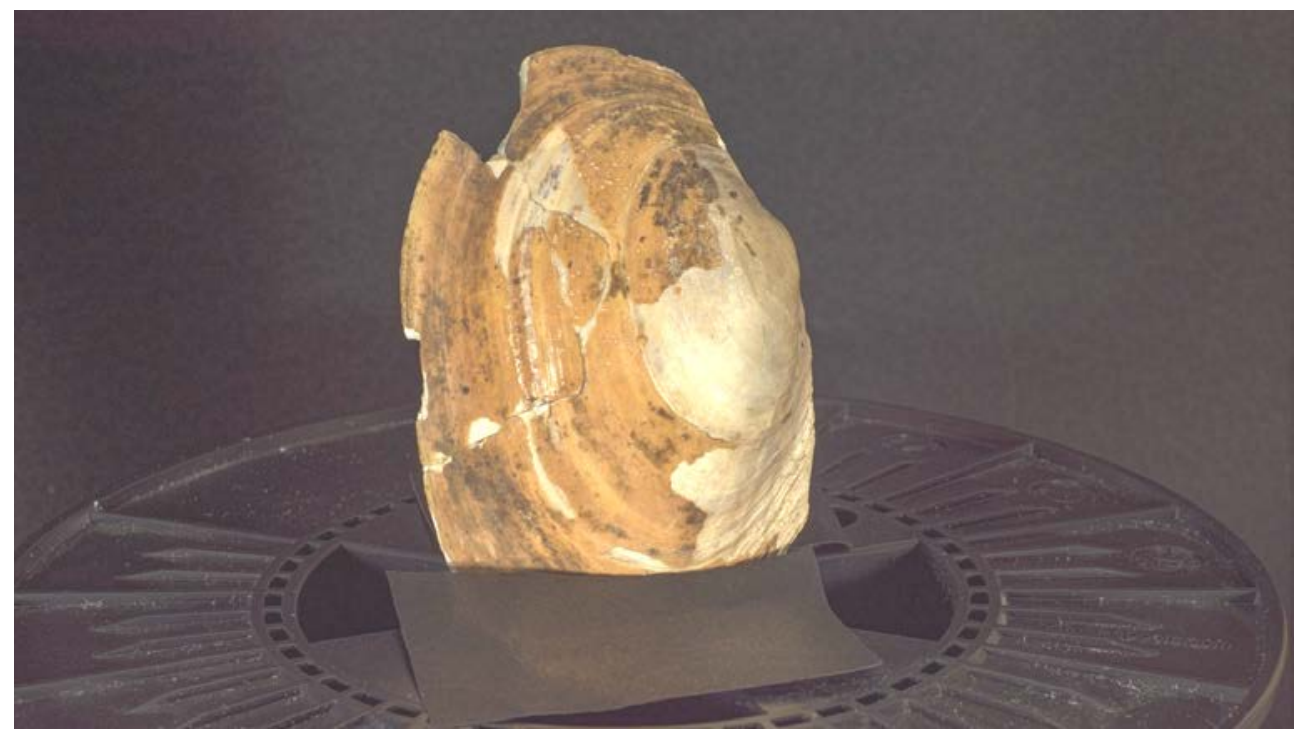

Fig. 2 - For the second set of photos the shell has been rotated upside down. 


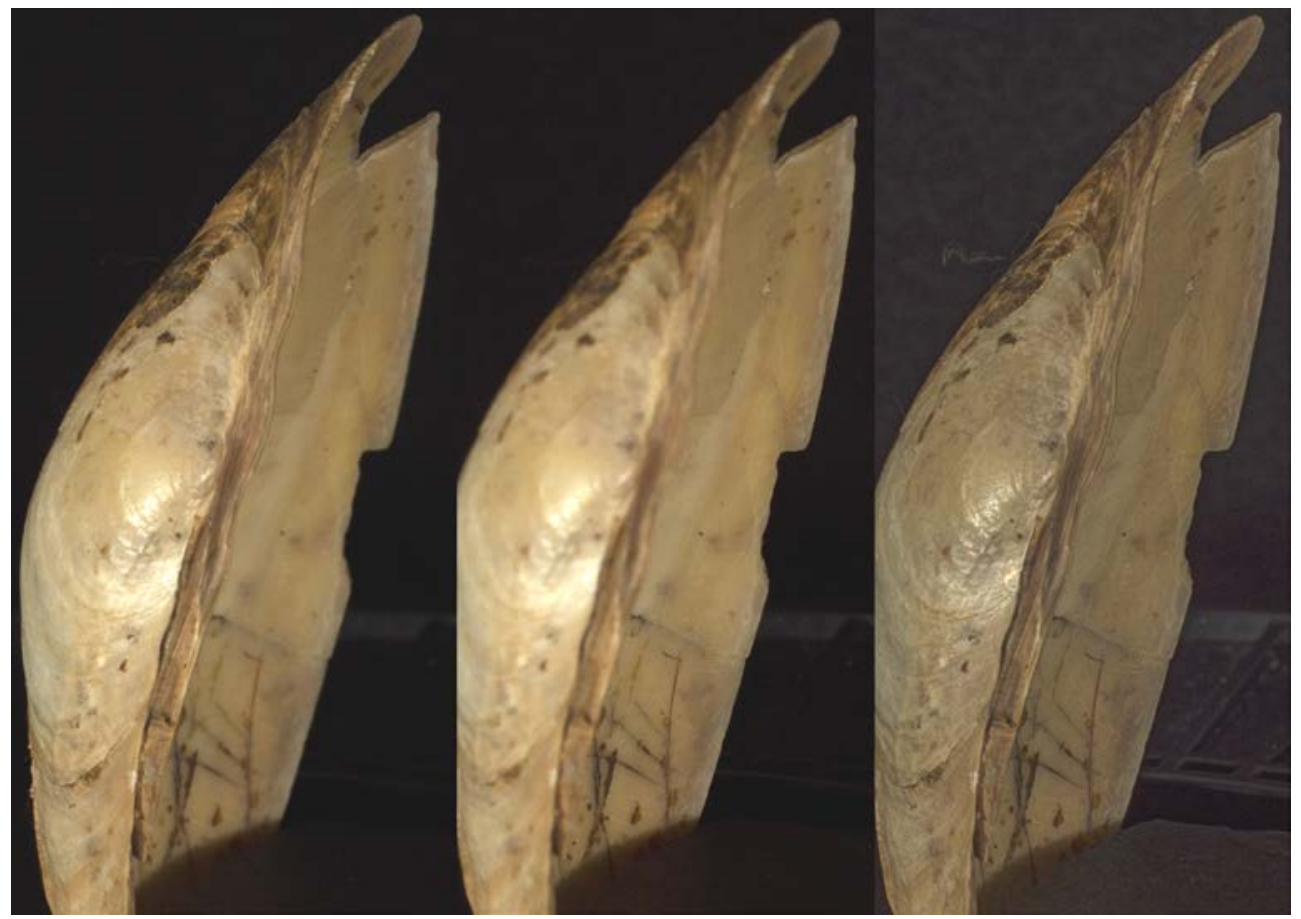

Fig. 3 - Same position on the turntable. Focus on the nearest (left) and on the farther (middle) point of the shell. Focus stacked image (right) with an extended depth of field.

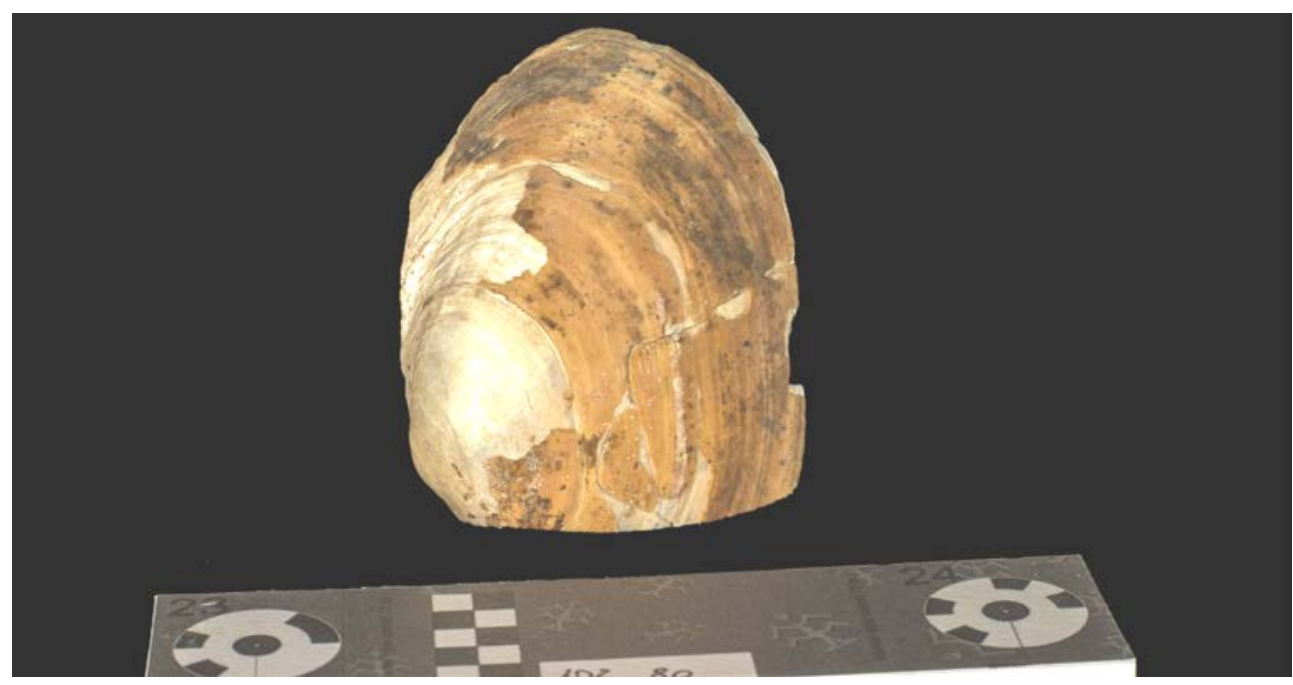

Fig. 4 - Resulting image ready to be processed for 3D modeling of TS.17.F.L135.1. 


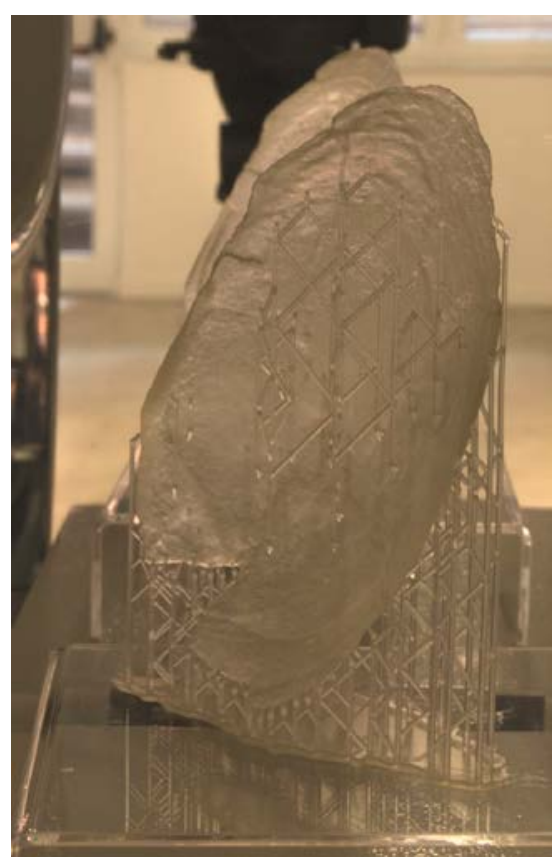

Fig. 5 - The replica with the support scaffolding.

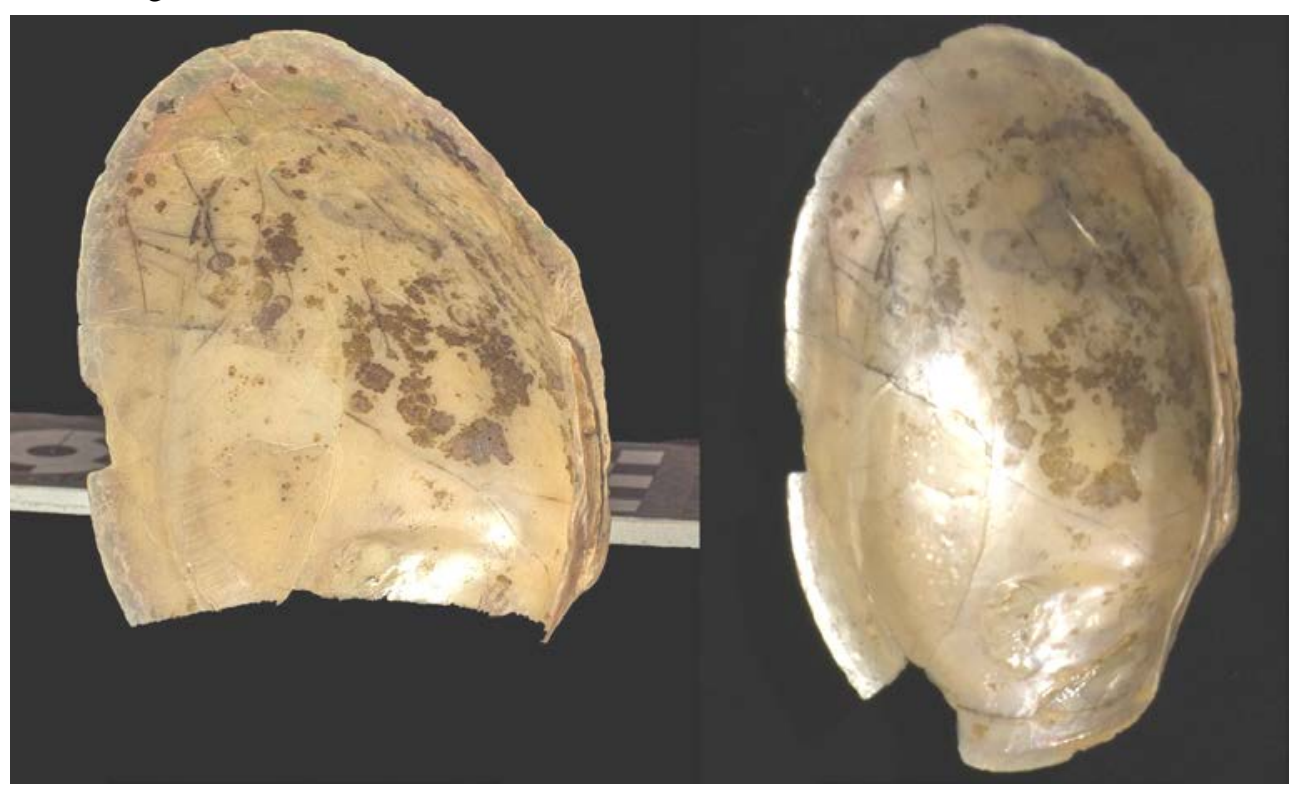

Fig. 7 - On the left almost every glare have been removed on shell TS.17.F.L135.

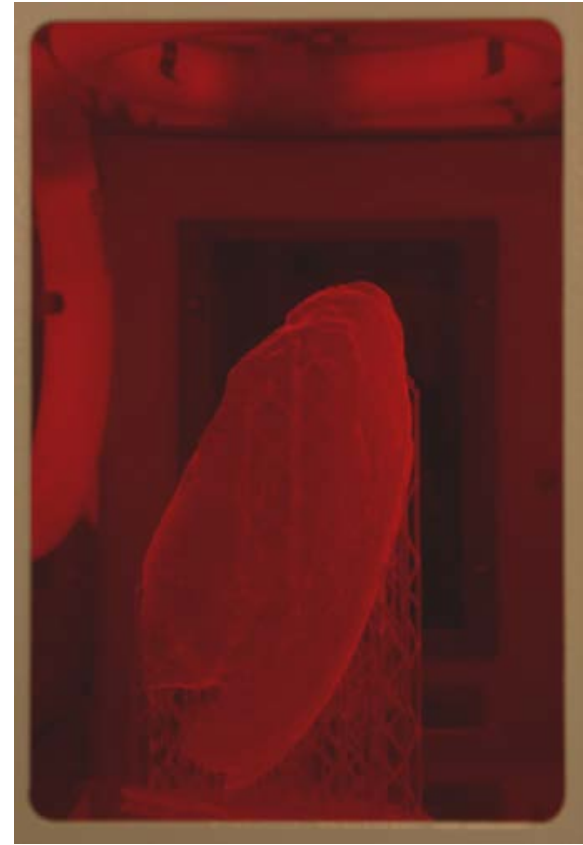

Fig. 6 - The replica in the post curing chamber. 

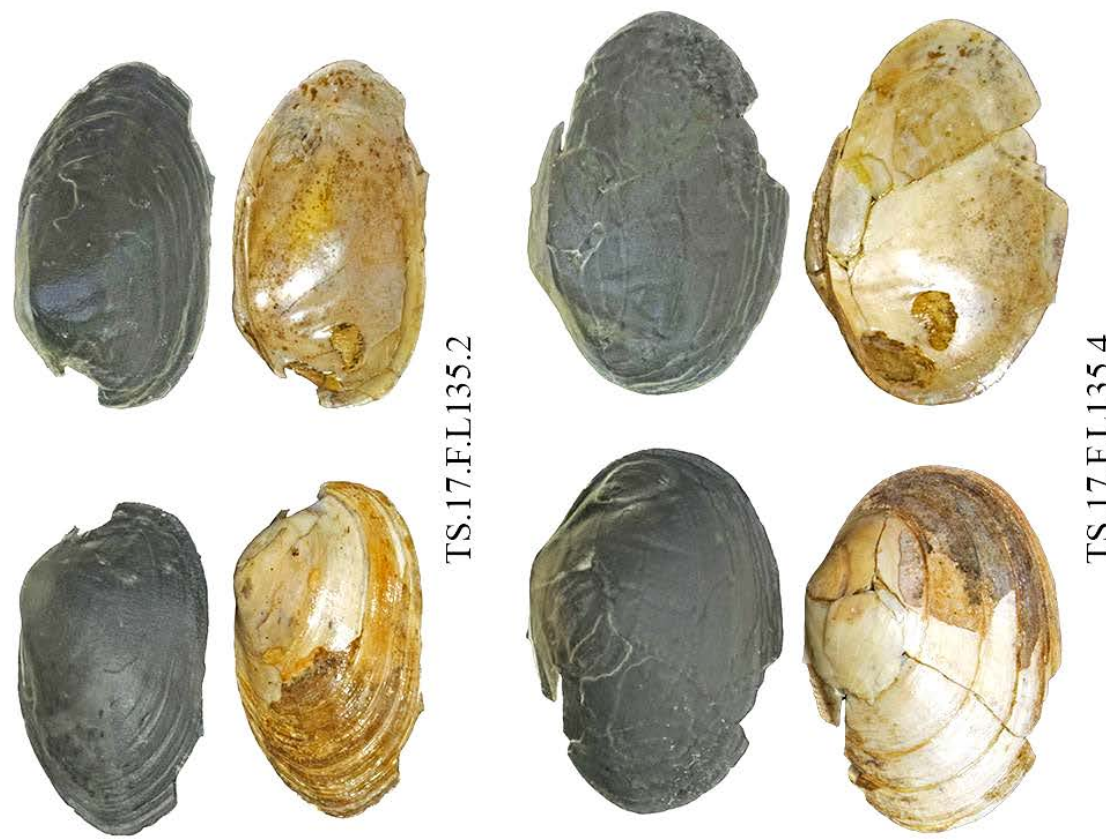

渵
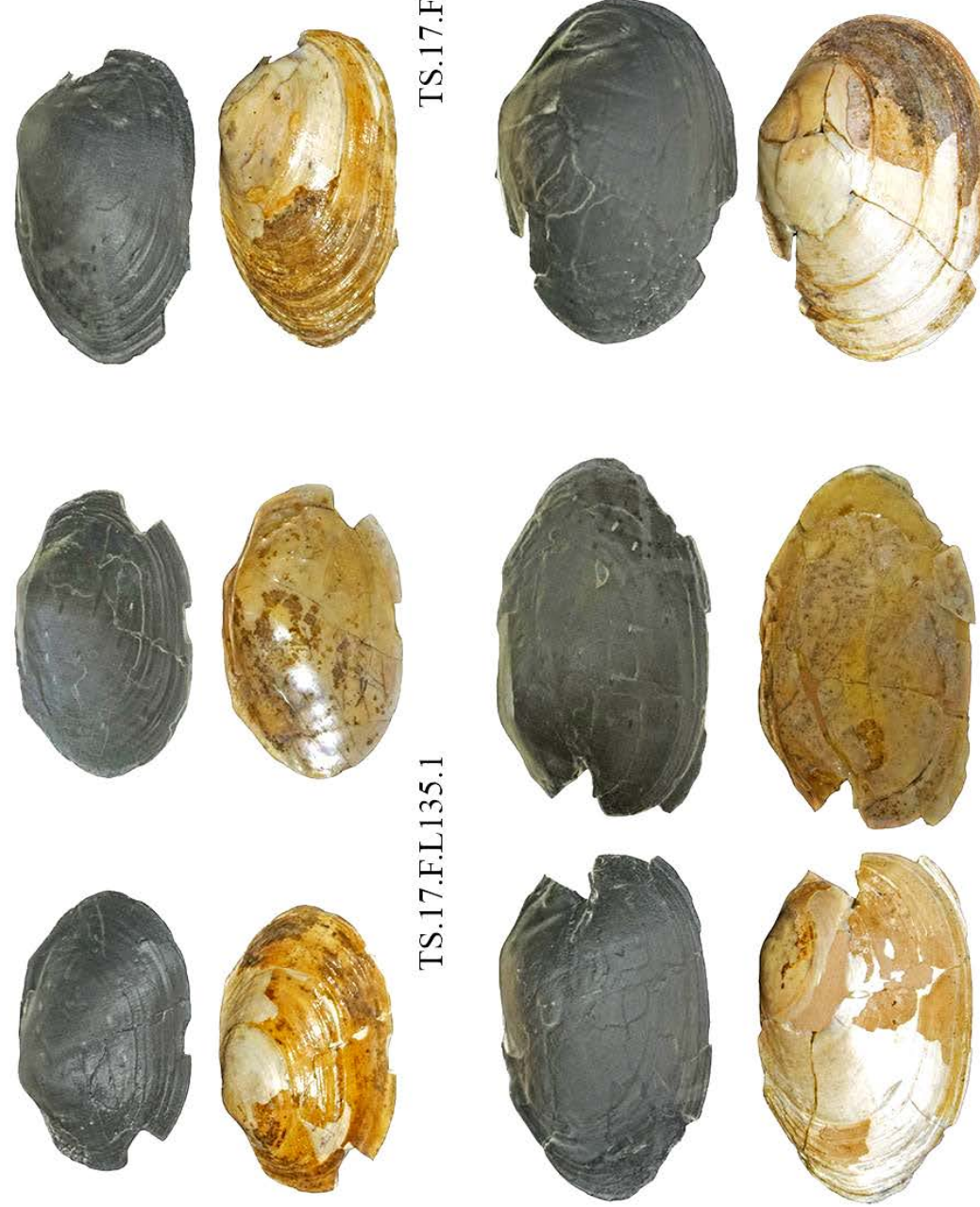

i.

I.

I.
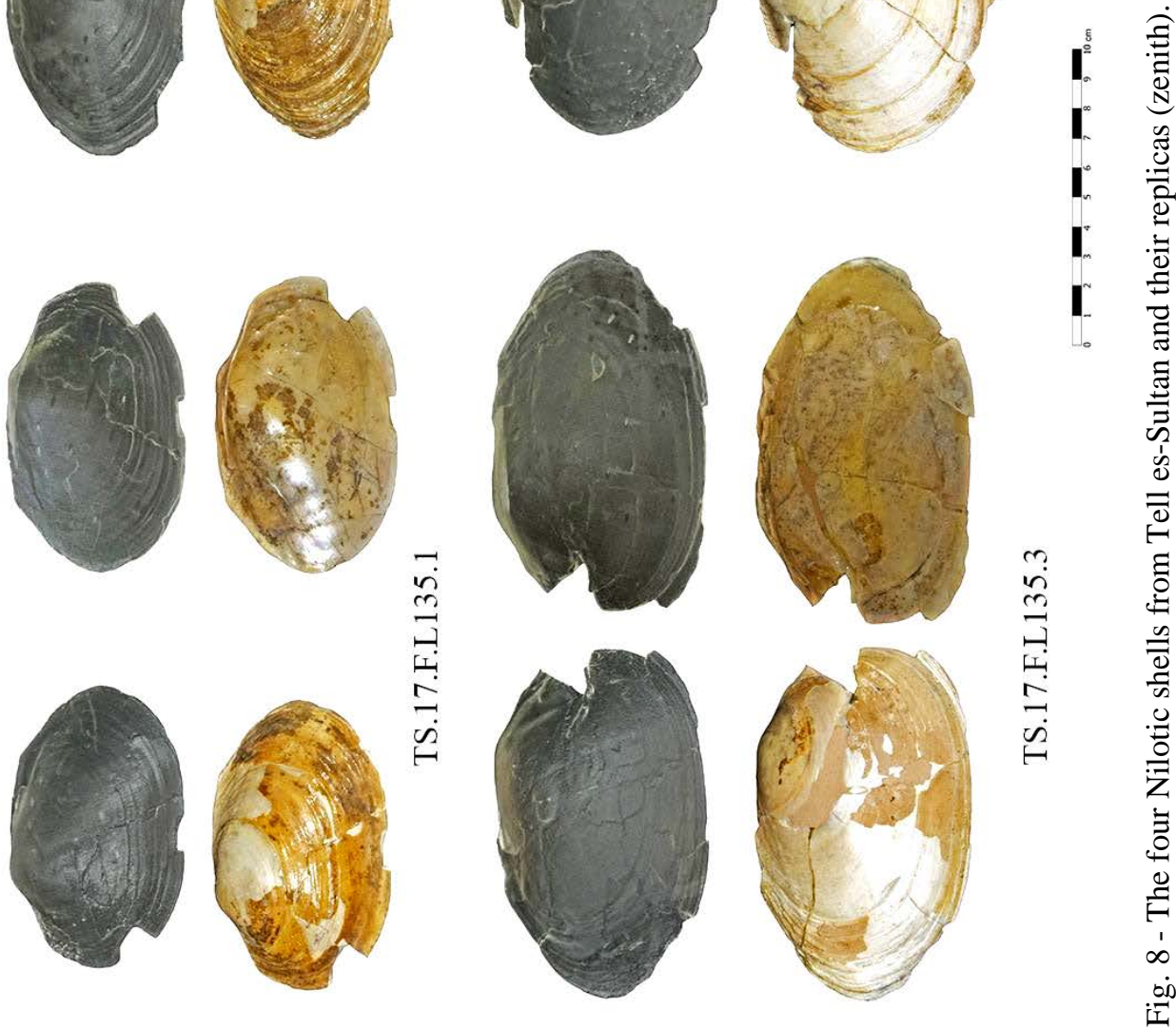

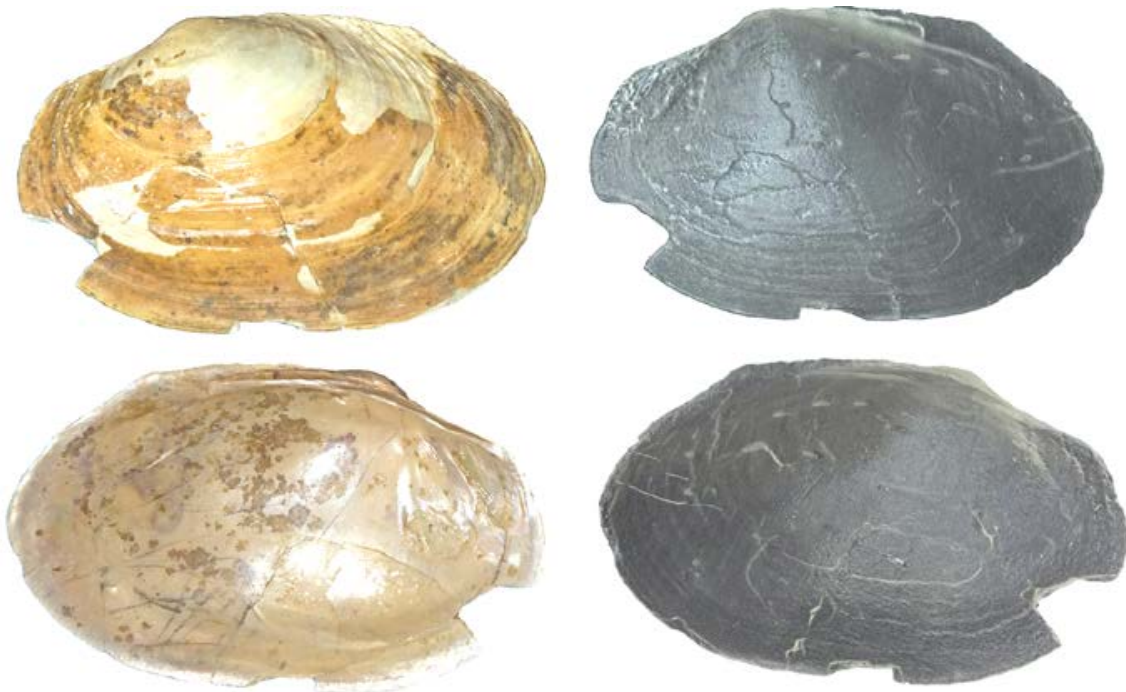

TS.17.F.L135.1

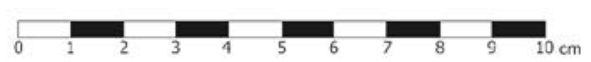

Fig. 9 - TS.17.F.L135.1 and its replica.
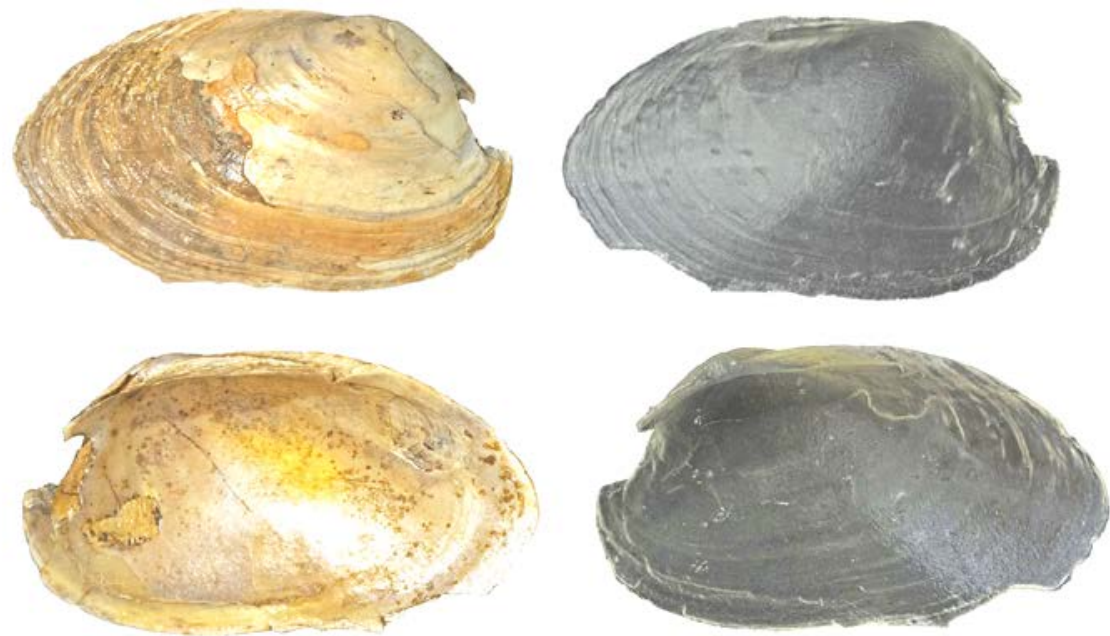

TS.17.F.L135.2

Fig. 10 - TS.17.F.L135.2 and its replica. 